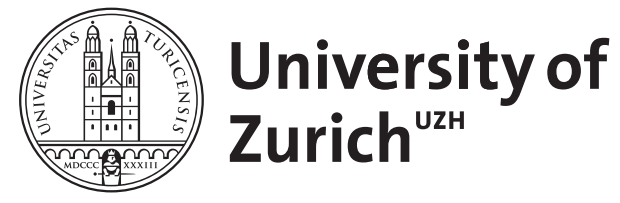
Archive

University of Zurich

University Library

Strickhofstrasse 39

CH-8057 Zurich

www.zora.uzh.ch

Year: 2012

\title{
Negotiating climate change
}

Michaelowa, Katharina ; Michaelowa, Axel

DOI: https://doi.org/10.1080/14693062.2012.693393

Posted at the Zurich Open Repository and Archive, University of Zurich

ZORA URL: https://doi.org/10.5167/uzh-65196

Journal Article

Accepted Version

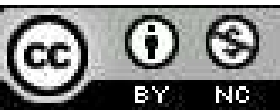

The following work is licensed under a Creative Commons: Attribution-NonCommercial 1.0 Generic (CC BY-NC 1.0) License.

Originally published at:

Michaelowa, Katharina; Michaelowa, Axel (2012). Negotiating climate change. Climate Policy, 12(5):527533.

DOI: https://doi.org/10.1080/14693062.2012.693393 


\title{
Negotiating Climate Change ${ }^{1}$
}

\author{
Axel \& Katharina Michaelowa \\ axel.michaelowa@pw.uzh.ch ; katja.michaelowa@pw.uzh.ch \\ University of Zurich, Center for Comparative and International Studies
}

This is the authors' accepted manuscript published in: Climate Policy12(5): 527-533, http://dx.doi.org/10.1080/14693062.2012.693393.

\section{Introduction}

In December 2009, the whole world looked at Copenhagen expecting the $15^{\text {th }}$ Conference of the Parties (COP 15) to the United Nations Convention on Climate Change (UNFCCC) to come up with a new treaty to address global climate change. Given the perceived urgency of the issue that had crystallized in the allocation of the 2007 Nobel Peace Prize to the IPCC and Al Gore, an unprecedented number of high-level diplomats and heads of state gathered in Copenhagen. All in all, more than 40'000 participants attended the negotiations as negotiators and observers, stretching the capacity of the conference venue. Church bells were ringing to symbolize the significance of the event for mankind as a whole, and the media were full of information on this memorable gathering.

Yet, COP 15 did not yield the expected outcome. The "Copenhagen Accord" saved the negotiation process from a complete failure and opened a back door to move on in the following years, but no agreement was reached on emissions commitments beyond 2012.

\section{Analysing the determinants of negotiation failures and successes}

Are country preferences so different that they cannot be reconciled? Or is there just a very strong expectation to be able to free-ride on other countries' efforts? Standard economic theory suggests that mitigation of climate change represents a prisoners' dilemma situation typically arising in the context of public goods' provision. As benefits from greenhouse gas emission reduction are nonrival and non-excludable on a global level, the incentive for free-riding is difficult to overcome. A number of studies highlighted different facets of this problem already at the early times of the international climate change negotiation process, and expressed strong scepticism about any possible success (Victor, 2001, Barrett, 1998, Finus, 2001). A central assumption of this literature is that there is no supranational institution that can impose a treaty with emissions mitigation commitments on governments and actually enforce compliance. Thus, emissions mitigation treaties need to be self-enforcing. This can be supported by limiting membership (Carraro and

\footnotetext{
${ }^{1}$ We gratefully acknowledge financial support by the Swiss Network for International Studies (SNIS) that has enabled us to carry out the research compiled in the special edition.
} 
Marchiori, 2003), or linking emissions mitigation treaties with agreements that cover different policy issues (Toth et al., 2001).

Yet, the successful entry into force of the Kyoto Protocol and the success of other international environmental agreements such as the Montreal Protocol convinced most scholars that, at least under certain conditions, progress can be reached (for a recent review, see Young, 2011). Apparently, simple game theoretic models do not sufficiently explain the outcome of negotiations. This is increasingly acknowledged by game-theorists themselves, who recognize that international cooperation can lead to reductions in transaction costs and the generation of trust (Finus and Rundshagen, 2006). Moreover, without international negotiations, the relevant actors may not even be able to acquire sufficient information to actually define their position (Haas et al. 1993).

Thus the negotiation process itself is important, as well as the specific legal and administrative system in which this process is embedded. The latter is covered by a strand of the literature in international law that discusses how global governance rules have evolved towards a system of administrative law, which is binding on countries, without even requiring explicit consent from national parliaments (see e.g. Gupta, this issue). The decisions of the subsidiary bodies to the UNFCCC are examples for this law. It is also become increasingly likely that emitters become liable on supranational and national levels (Faure and Peeters, 2011). Such legal conditions influence the incentives of the different parties in the negotiation process, and, most crucially, their willingness to find a consensus. In addition, many factors related to specific characteristics of the individual delegations influence negotiation outcomes. In fact, much of the success or failure of a UNFCCC meeting seems to depend on the negotiation skills and tactical moves of the conference presidency, and on strategies employed by the different country delegations. In a critical situation at COP 3 in Kyoto 1997 similar to the last days of Copenhagen, a skilful handling of the final night negotiations by COP president Estrada led to the agreement of the Kyoto Protocol (Depledge, 2005). In contrast, the inept handling of the Copenhagen conference by the Danish Prime Minister Rasmussen - who even did not know the basic rules of procedure of the UNFCCC - contributed to its failure (Michaelowa, 2010).

International negotiation theory developed in the realm of political science / international relations theory (see, e.g., Odell, 2000, and 2006) focuses precisely on these particular strategies and their potential for success. They also consider that individual negotiators' (or country delegations') skills and strategic approaches may interact with the countries' exogenous characteristics such as their power resources, and with the perceived salience of the particular issue at hand (see Bailer, this issue). From this perspective, it becomes possible not only to analyse the general probability of reaching an agreement, but also to assess the advantages and 
disadvantages of certain strategic choices for individual country delegations and their success in the international negotiation process.

Some particularly interesting countries to examine are the large emerging economies of Brazil, China, India and South Africa (BASIC), which have become crucial players in the context of the UNFCCC. Narlikar (2010) analyzes some general features of their negotiation behaviour across different international policy areas. This special issue "Negotiating Climate Change" includes a case study for India (Michaelowa and Michaelowa). Another country-case included is Russia, which, as the fourth largest emitter of greenhouse gases after China, the US and the EU, and due to its control over a large share of the world's known fuel resources, is an important player, and yet, its strategies have been poorly understood so far (see Andonova and Alexieva, this issue).

In addition, it appears to be at least as important to analyze the strategic options for poor developing countries. Many of these countries are expected to suffer the most from the consequences of climate change while, at the same time, being the least responsible for this development. By definition, they lack the external power resources that help richer countries push through their positions. Yet, climate change negotiations have revealed that even very small and economically powerless countries such as those of the Alliance of Small Island States (AOSIS) may at times become quite influential (see Betzold et al., this issue). At the same time, large and economically extremely powerful countries like the United States have been sidelined, at least to some extent, in the context of the Kyoto-Protocol.

What drives the positions taken up at the international level, and the strategies used, and which of these strategies appear to be successful? This special edition makes use of a number of complementary qualitative and quantitative methods to answer these questions. Using crosscountry regression analysis, the first two papers on the determinants of success (Weiler, this issue) and of negotiation strategies (Bailer, this issue) present a number of regularities that are re-examined in the subsequent case studies on India (Michaelowa and Michaelowa, this issue), AOSIS (Betzold et al., this issue) and Russia (Andonova and Alexieva, this issue). The case studies thus deepen the analyses of the general papers. In some cases, they also provide support for theoretical hypotheses whose results remain ambiguous in the general papers due to data constraints and difficulties regarding comparable variable specification. Moreover, a conceptual paper from a wider theoretical perspective (Gupta, this issue) examines the role of normative principles and the legal setting, and their impact on the individual country positions and strategies.

All studies in this volume use a common database, which includes three novel data sets developed in the framework of a two-year joint research project funded by the Swiss Network for International Studies (SNIS). The first data set is derived from a series of interviews with country delegates and the second from hand coding of country submissions to the UNFCCC secretariat. 
The third dataset is based on country statements made during the negotiations as reported by the Earth Negotiation Bulletin. The data covers the period from COP 13 in Bali $2007^{2}$ to COP 16 in Cancun 2010 with an emphasis on the period around Copenhagen. A detailed discussion of this data is provided in the Appendix 1 of Weiler (this issue).

\section{Negotiating climate change: some key results}

While each of the individual papers in this volume presents a wealth of specific conclusions and policy recommendations, this section focuses on selected topics that appear across the different studies whatever their focus and methodology:

A) The role of the national political economy

B) The role of accepted norms

C) The role of delegation characteristics

The discussion of these topics will provide some insights into interesting results of this special edition, along with an illustration of the complementarities between the econometric, theoretical and case study analysis used in the different studies.

\section{A) The role of the national political economy}

Both the Indian and the Russian case studies stress the necessity to understand the positions and strategies adopted at the UNFCCC not simply as a product of international interaction during the conferences, but also as a product of the national political economies influenced by local constituencies. For India, there is strong evidence that international positions have changed along with the emergence of a national climate policy dialogue that was induced, among other things, by a broader understanding of India's own vulnerability to climate change, by the awareness that long-term growth anyway requires some improvements in national energy efficiency, and by the awareness of the benefits of the Kyoto Protocol's market mechanisms for private business (Michaelowa and Michaelowa, this issue). All three areas have become relevant for Russia as well (Andonova and Alexieva, this issue). This is true despite the fact that, as opposed to India, Russia's vulnerability to climate change is somewhat compensated by benefits of climate change in some sectors, and that through its control over large fossil fuel reserves, the country is not directly constrained by a shortage in energy resources. Business launched a strong protest when the Russian government announced at COP 17 in Durban that it would not participate in the $2^{\text {nd }}$

${ }^{2}$ COP 13 was chosen because it defined the "Bali Roadmap" specifying that a new treaty should be finalized by COP 15 . 
commitment period of the Kyoto Protocol. However, due to the crucial role of the presidency and government bureaucracy private business interest eventually appears to have little impact.

The limited role of business in Russia's autocratic setting supports the most central outcome by Bailer (this issue) who links the use of different strategies to national political institutions in a sample of about fifty countries. She finds that governments of democratic countries, although generally using more accommodating, value creating strategies, tend to use hard strategies when strong national lobby interests are concerned. The role of national interest groups diminishes (and eventually even turns to the opposite effect) for mixed or authoritarian regimes.

\section{B) The role of accepted norms}

All the studies in this special edition demonstrate the important role of accepted norms. Gupta (this issue) discusses how scientific developments over the last twenty years have helped to establish a consensus on the existence of man-made climate change. She also finds that this scientific consensus rendered the problem more "structured", which should help finding an agreement. The emergence of the consensus and its implications are further illustrated by the examples of India (Michaelowa and Michaelowa, this issue) and Russia (Andonova and Alexieva, this issue). Clearly, it effectively deprived large emitter countries of their previous excuse for taking no action, and allowed countries jeopardized by climate change to benefit from the moral appeal of their positions and strategies. Even India found itself under substantial pressure when it was accused by other developing countries such as Bangladesh and the Maldives to be responsible for the 2009 deadlock in the international negotiation process.

An even more impressive case of moral persuasion is discussed in the study of AOSIS, which has achieved notable success by alerting the world to the dramatic consequences its members will suffer given other countries' irresponsible level of greenhouse gas emissions (Betzold et al., this issue). In his cross-sectional analysis of 56 countries Weiler (this issue) finds that, at given levels of other important determinants of negotiation success (such as external power resources measured in terms of GDP), vulnerability to climate change is generally linked significantly and positively to success in the international climate negotiations. In addition, these highly vulnerable countries tend to make more use of hard negotiation strategies (Bailer, this issue).

While norms have been developed, accepted and successfully applied with respect to the scientific core questions of climate change, norms have not yet been developed regarding the question "who should take action where, when and why" (Gupta, this issue). How to allocate responsibilities and rights will thus be one of the most urgent challenges to negotiations in the coming years. 


\section{C) The role of delegation characteristics}

Apart from external power resources, such as GDP which is obviously important for success in international negotiations, and characteristics with a less obvious, but nonetheless strongly significant effect such as vulnerability (as highlighted above), internal power resources such as particular characteristics of the national delegation are typically considered in negotiation analysis. Just as similar studies in other fields of analysis, all empirical papers in this special edition primarily look at delegation size and the experience of the delegation leader because data for these variables can be most easily obtained in a way that is comparable across countries. However, the role of these variables appears much less strong than expected. Only the Russian case study fully corresponds to the expectations. For Russia, the empirical analysis shows a high score on scale of the different indicators of negotiation success (note, e.g., the tremendous concessions Russia obtained when presenting itself as the pivotal player that eventually allowed the Kyoto-Protocol to enter into force), a constantly large delegation, and a delegation leader with about fifteen years of diplomatic experience in the field (Andonova and Alexieva, this issue). However, looking at the details of the case study, one also notices that this does not translate into the activities that would usually be expected to provide the causal channel between internal power resources and success. In fact, despite its size and experience, the Russian delegation has remained relatively silent and inactive over the whole period of analysis. The Indian case study fully opposes the expected link. Throughout the years, the Indian delegation has always been remarkably small and yet successful in various dimensions - and notably so, when in 2009 the lead of the delegation was taken over by the new Minister of Environment and Forests Jairam Ramesh, who had absolutely no prior diplomatic experience in this field (Michaelowa and Michaelowa, this issue). Regarding AOSIS the size of individual country delegations was usually extremely small. It has increased over time, but if anything, this is interpreted as a factor that may have diverted these countries from their common objectives, and thus reduced their chances of success (Betzold et al., this issue). In the cross-country regressions presented by Weiler (this issue), delegation size is not significant in any of the specifications.

However, case study evidence from AOSIS and India reveals that this should not be interpreted as evidence for the irrelevance of internal power resources. While large-n cross-country studies (such as Weiler, this issue; and Bailer, this issue) cannot go beyond the use of the above mentioned rough indicators, case studies can specify more refined attributes of the individual delegations. For the success of AOSIS, for instance, skilled leadership and the strong integration of outside expertise (from NGOs and legal scholars) into the delegation was deemed crucial for the group's success (Betzold et al., this issue, especially footnote 10). In India, the above mentioned minister did not have any diplomatic experience in the field, but more than compensated this by past as an MIT trained economist and experienced statesman, who had already held other ministerial 
positions, and who was very close to Prime Minister Manmohan Singh and to the national media (notably for having managed the government's successful national election campaign). Under his influence, climate change became a relevant topic in the Indian press, and India opened up internationally to become a proactive deal-maker with substantial value creating elements in its negotiation strategy at the level of the UNFCCC (Michaelowa and Michaelowa, this issue; for some more details, see also Michaelowa and Michaelowa, 2011).

Moreover, an interesting feature of the Indian delegation is its continued reliance on experienced and knowledgeable delegation members, even if they change office, e.g. move from one ministry to the next, to academia, or even to foreign development agencies (Michaelowa and Michaelowa, this issue). This could provide an interesting role model for other developing country delegations, who often struggle to find experienced delegation members given the important fluctuation of senior civil servants.

\section{Open questions}

Some other questions have to remain open here and call for further research. One major issue is the interaction of different countries' strategies. In this special edition, this issue is taken up explicitly only by Gupta's theoretical article. She suggests that the negotiations can substantially move forward only when all partners adopt value creating strategies and are ready to compromise. Another topic that has been only marginally explored by the studies in this volume is issue linkage across different fields of international negotiation. An exception is the paper by Andonova and Alexieva (this issue) who explain that WTO membership was an additional carrot attracting Russia to ratify the Kyoto Protocol. Gupta (this issue) addresses this topic from a more general perspective. She further notes possible issue-linkage between different topics within the UNFCCC negotiations. The multiplication of specific issues on the agenda has enlarged the win-set and possibly allows the parties to more easily find a compromise to the benefit of all. At the same time, new issues like LULUCF and REDD have weakened the cohesion of AOSIS (Betzold et al., this issue), which may reduce the odds of an agreement that is convincing from an environmental perspective. Thus when adding more topics and increasing complexity, it is not a priori clear whether this will be helpful or not (Gupta, this issue).

It should be noted that the concept of "success" also changes between these two perspectives. In one case, reaching a compromise is in itself considered a success, while in the other case, success is seen primarily as a function of climate change mitigation. This is not necessarily the same. From an individual country's perspective, there are even more ways to define success: First, success in terms of negotiation outcomes being as close as possible to a country delegation's initial positions; second, success in terms of the national and international reputation earned by the delegation; 
and third, success in terms of the "true needs" of the country's population that may differ from the perceived preferences (or perhaps special interests) defended by the national delegation. When considering that the negotiations have not actually been completed, measurement of success in any of these dimensions becomes an even more daunting exercise. The outcome effectively becomes a moving target and not getting anything today may mean getting more tomorrow. Even the expected "best alternative to a negotiated agreement" (BATNA), i.e., the situation with which a country should compare any proposal in order to decide about whether to go for or against it, must be conceived as non-stable, but dynamic, and changing over time and from one meeting to the next.

This generates difficulties in analysing UNFCCC negotiations as compared to, e.g., negotiations at the European Union, to which negotiation theory has been applied much more frequently (see, e.g., Bailer, 2004, 2010). These methodological difficulties could not be solved by the studies compiled in this volume. However, the presentation of different concepts, indicators and research methods should help the reader to build his opinion on the issues at hand.

Overall, the set of papers in this special edition provides unique insights into details of the UNFCCC negotiation process based on data that have never been explored so far, and on complementarities between quantitative and qualitative research methods. For this reason, it should be relevant for the climate policy community, academics and practitioners alike. Even for scholars not primarily interested in climate change related issues, it should be of interest as a new application of negotiation theory.

\section{References}

Bailer, S., 2004, 'Bargaining success in the European Union: the impact of exogenous and endogenous power resources', European Union Politics 5(1), 99-123.

Bailer, S., 2010, 'What factors determine bargaining power in the EU?', Journal of European Public Policy 17(5), 743-752.

Barrett, S. 1998, 'Political economy of the Kyoto Protocol', Oxford Review of Economic Policy, 14(4), 20-39.

Carraro, C., Marchiori, C. 2003, 'Stable coalitions, globalization of the world economy', in: Carraro, C. (ed.): Governing the global environment, Edward Elgar, Cheltenham.

Depledge, J. 2005. The Organization of Global Negotiations: Constructing the Climate Change Regime, Earthscan, London.

Faure, M., Peeters, M. (eds.) 2011, Climate change liability, Edward Elgar, Cheltenham. 
Finus M. 2001, Game Theory and International Environmental Cooperation, Edward Elgar, Cheltenham.

Finus M., Rundshagen, B. 2006, 'Participation in international environmental agreements: The role of timing and regulation', Natural Resource Modeling 19, 165-200.

Haas P., Keohane, R., Levy, M. 1993. Institutions for the Earth: sources of effective International environmental protection, MIT Press, Cambridge.

Michaelowa, A. 2010, 'The Copenhagen failure and its consequences for international climate policy', Intereconomics, 45, 2-3.

Michaelowa, K., Michaelowa, A. 2011, India in the international climate negotiations: from traditional nay-sayer to dynamic broker, CIS Working Paper No. 70, Center for Comparative and International Studies, ETH and University of Zurich, Switzerland.

Narlikar, A., 2010, New powers: how to become one and how to manage them, Columbia University Press, New York.

Odell, J., 2000, Negotiating the world economy, Cornell University Press, New York.

Odell, J. 2006, Negotiating Trade: Developing Countries in the WTO and NAFTA, Cambridge University Press, Cambridge.

Toth F., Mwandosya, M., Carraro, C., Christensen, J., Edmonds, J., Flannery, B., Gay-Garcia, C., Lee, H., Meyer-Abich, K., Nikitina, E., Rahman, A., Richels, R., Ruqiu, Y., Villavicencio, A., Wake, Y., Weyant, J. 2001, Decision-making frameworks, in: Metz, B.; Davidson, O., Swart, R.; Pan, J. (eds.): Climate Change 2001: Mitigation, Cambridge University Press, Cambridge, 601688.

Victor, D., 2001, The failure of the Kyoto Protocol, Princeton University Press, Princeton.

Young, O., 2011, 'Effectiveness of international environmental regimes: Existing knowledge, cutting-edge themes, and research strategies', Proceedings of the National Academy of Sciences of the United States of America (PNAS) 108(50), 19853-19860. 